\title{
Effects of outdoor ranging on external and internal health parameters for hens from different rearing enrichments
}

\author{
Md Saiful Bari ${ }^{1,2}$, Yan CSM Laurenson ${ }^{2}$, Andrew M Cohen-Barnhouse ${ }^{1,2}$, Stephen W Walkden-Brown ${ }^{2}$, Dana LM \\ Campbell ${ }^{\text {Corresp. } 1}$ \\ ${ }^{1}$ Agriculture and Food, Commonwealth Scientific and Industrial Research Organisation (CSIRO), Armidale, New South Wales, Australia \\ 2 School of Environmental and Rural Science, University of New England, Armidale, New South Wales, Australia \\ Corresponding Author: Dana LM Campbell \\ Email address: Dana.Campbell@csiro.au
}

In Australia, free-range layer pullets are typically reared indoors, but adult layers go outdoors, this mismatch might reduce adaptation in laying environments. Enrichments during rearing may optimise pullet development and subsequent welfare as adult freerange hens. In the outdoor environment, hens may have greater opportunities for exercise and natural behaviours which might contribute to improved health and welfare. But the outdoor environment may also result in potential exposure to parasites and pathogens. Individual variation in range use may thus dictate individual health and welfare. This study was conducted to evaluate whether adult hens varied in their external and internal health due to rearing enrichments and following variation in range use. A total of $1386 \mathrm{Hy}$-Line Brown ${ }^{\circledR}$ chicks were reared indoors across 16 weeks with 3 enrichment treatments including a control group with standard housing conditions, a novelty group providing novel objects that changed weekly, and a structural group with custom-designed structures to increase spatial navigation and perching. At 16 weeks of age the pullets were moved to a free-range system and housed in 9 identical pens within their rearing treatments. All hens were leg-banded with microchips and daily ranging was assessed from 25 to 64 weeks via radio-frequency identification technology. At 64-65 weeks of age, 307 hens were selected based on their range use patterns across 54 days up to 64 weeks: indoor (no ranging), low outdoor (1.4 h or less daily), and high outdoor (5.2-9 h daily). The external and internal health and welfare parameters were evaluated via external assessment of body weight, plumage, toenails, pecking wounds, illness, and post-mortem assessment of internal organs and keel bones including whole-body CT scanning for body composition. The control hens had the lowest feather coverage $(P<0.0001)$ and a higher number of comb wounds $(P=0.03$ ) than the novelty hens. The high outdoor rangers had fewer comb wounds than the indoor hens $(P=0.04)$, the shortest toenails $(P<0.0001)$ and the most feather coverage $(P<0.0001)$, but lower body weight $(P<0.0001)$ than the 
indoor hens. High outdoor ranging decreased both body fat and muscle (both $P<0.0001$ ). The novelty group had lower spleen weights than the control hens $(P=0.01)$ but neither group differed from the structural hens. The high outdoor hens showed the highest spleen $(P=0.01)$ and empty gizzard weights $(P=0.04)$. Both the rearing enrichments and ranging had no effect on keel bone damage (all $P \geq 0.19$ ). There were no significant interactions between rearing treatments and ranging patterns for any of the health and welfare parameters measured in this study $(P \geq 0.07)$. Overall, rearing enrichments had some effects on hen health and welfare at the later stages of the production cycle but subsequent range use patterns had the greatest impact. 
1 Effects of outdoor ranging on external and internal

2 health parameters for hens from different rearing

3 enrichments

4

5 Md Saiful Bari ${ }^{1,2}$, Yan C.S.M Laurenson ${ }^{1}$, Andrew M. Cohen-Barnhouse ${ }^{1,2}$, Stephen W.

6 Walkden-Brown $^{1}$ and Dana L.M. Campbell ${ }^{2 *}$

7

$8{ }^{1}$ School of Environmental and Rural Science, University of New England, Armidale, New South

9 Wales, Australia

$10{ }^{2}$ Agriculture and Food, Commonwealth Scientific and Industrial Research Organisation

11 (CSIRO), Armidale, New South Wales, Australia

12

13

14

15

* Corresponding author:

Dana Campbell

New England Highway, Armidale, New South Wales, 2350, Australia

16

17

18

19

20

21

22 


\section{Abstract}

In Australia, free-range layer pullets are typically reared indoors, but adult layers go outdoors, this mismatch might reduce adaptation in laying environments. Enrichments during rearing may optimise pullet development and subsequent welfare as adult free-range hens. In the outdoor environment, hens may have greater opportunities for exercise and natural behaviours which might contribute to improved health and welfare. But the outdoor environment may also result in potential exposure to parasites and pathogens. Individual variation in range use may thus dictate individual health and welfare. This study was conducted to evaluate whether adult hens varied in their external and internal health due to rearing enrichments and following variation in range use. A total of 1386 Hy-Line Brown ${ }^{\circledR}$ chicks were reared indoors across 16 weeks with 3 enrichment treatments including a control group with standard housing conditions, a novelty group providing novel objects that changed weekly, and a structural group with custom-designed structures to increase spatial navigation and perching. At 16 weeks of age the pullets were moved to a freerange system and housed in 9 identical pens within their rearing treatments. All hens were legbanded with microchips and daily ranging was assessed from 25 to 64 weeks via radio-frequency identification technology. At 64-65 weeks of age, 307 hens were selected based on their range use patterns across 54 days up to 64 weeks: indoor (no ranging), low outdoor (1.4 h or less daily), and high outdoor (5.2-9 $\mathrm{h}$ daily). The external and internal health and welfare parameters were evaluated via external assessment of body weight, plumage, toenails, pecking wounds, illness, and post-mortem assessment of internal organs and keel bones including whole-body CT scanning for body composition. The control hens had the lowest feather coverage $(P<0.0001)$ and a higher number of comb wounds $(P=0.03)$ than the novelty hens. The high outdoor rangers had fewer comb wounds than the indoor hens $(P=0.04)$, the shortest toenails $(P<0.0001)$ and the most feather coverage $(P<0.0001)$, but lower body weight $(P<0.0001)$ than the indoor hens. High outdoor ranging decreased both body fat and muscle (both $P<0.0001$ ). The novelty group had lower spleen weights than the control hens $(P=0.01)$ but neither group differed from the structural hens. The high outdoor hens showed the highest spleen $(P=0.01)$ and empty gizzard weights $(P=0.04)$. Both the rearing enrichments and ranging had no effect on keel bone damage (all $P \geq 0.19$ ). There were no significant interactions between rearing treatments and ranging patterns for any of the health and welfare parameters measured in this study $(P \geq 0.07)$. Overall, rearing enrichments had some effects on hen health and welfare at the later stages of the production cycle but subsequent range use patterns had the greatest impact.

\section{Introduction}

Free-range egg production is prevalent within Australia as consumers perceive free-range eggs to be healthier and tastier than caged eggs (Bray \& Ankeny, 2017). The free-range system is also perceived to improve hen welfare (Pettersson et al., 2016a) as hens have the choice to move 
freely outdoors, are exposed to daylight, and have greater opportunities for exercise and natural behaviors which might contribute to improved health and welfare. However, free-range systems can comparatively also bring increased risk of disease (Fossum et al., 2009), heat stress (Singh et al., 2017), predation (Bestman \& Wagenaar, 2014), parasites (Permin et al., 1999), vent-pecking (Bestman \& Wagenaar, 2014), and mortality (Bestman \& Wagenaar, 2014; Singh et al., 2017; Richards et al. 2012). Furthermore, it is well documented both within Australia and internationally that range use varies by individual choice with some hens ranging daily while others do not range at all (Larsen et al., 2017; Pettersson et al., 2016b). This variation could result in large differences in activity and diet between hens which may impact health and welfare such as influencing body composition by lowering body fat accumulation (Crespo \& EsteveGarcia, 2001; Renema et al., 1999; Sun et al., 2006) and strengthening the bones (Regmi et al., 2016) and muscles (Casey-Trott et al., 2017a ). Although recent work with commercial freerange layers showed no relationship between range use and tibial bone strength (Kolakshyapati et al., 2019).

Range use has been shown to impact external welfare parameters of hens. Individually tracked free-range hens that use the outdoor area more, show less feather damage than hens that prefer to spend time indoors (Mahboub et al., 2004; Rodriguez-Aurrekoetxea \& Estevez, 2016). Similarly, opportunistic scoring of hens on the range has shown better plumage condition compared with hens scored in the shed (De Koning et al., 2018) and better plumage in hens that ranged farther (Chielo et al., 2016). Outdoor ranging hens or hens that have access to a range area show comparatively reduced footpad dermatitis (Heerkens et al., 2016; RodriguezAurrekoetxea \& Estevez, 2016) and range use keeps toenails shortened (Campbell et al., 2017; Yilmaz Dikmen et al., 2016). However, not all studies demonstrate strong relationships between individual ranging and welfare parameters. Larsen et al. (2018) found no association between range access and comb colour, beak, footpad, plumage, or keel bone condition, although hens that ranged further had better beak condition and darker comb colour. Ranging is related to hen body weight, but the direction of the relationship varies between studies rendering this relationship currently equivocal (Campbell et al., 2016; Hartcher et al., 2016; Singh et al., 2016). Range use can also impact internal health and welfare parameters but data on individual patterns are currently limited. Ranging hens may have improved digestive and gut function over non-ranging hens as they ingest stones and grit that eventually contribute to heavier gizzards (Singh et al., 2016). Keel bone damage can reduce pop-hole usage, but the causal relationship is unclear (Richards et al. 2012). Furthermore, Kolakshyapati et al. (2019) recently showed no relationship between high and low range use and keel bone damage. Ranging hens might be susceptible to internal parasite infections such as Ascaridia galli that are present in soil (Kaufmann et al., 2011; Permin et al., 1999) as well as the range being contaminated by previous batches of hens (Höglund \& Jansson, 2011). But some research shows a reduction in flock level parasitic infections with increased range use (Sherwin et al., 2013) as the outdoor hens excrete more in the range and less indoors thus lowering the density of faeces and possibility of reinfection (Sherwin et al., 2013). Necropsies of hens from varying housing systems in Sweden 
119

120

121

122

123

124

125

126

127

128

129

130

131

132

133

134

135

136

137

138

139

140

141

142

143

144

145

146

147

148

149

150

151

152

153

154

155

156

157

158

showed a higher occurrence of viral and bacterial infections and diseases in free-range and floorbased systems (Fossum et al., 2009). Overall, there is minimal information on both external and internal health and welfare parameters of individual free-range hens that vary in their range use patterns.

For optimising the health and welfare of adult hens, it has been suggested to provide similar environments for both the rearing and layer housing (Janczak \& Riber, 2015). In Australian free-range systems (and elsewhere), the pullet rearing and adult housing environments are dissimilar. Adult hens range outdoors but the pullets are reared indoors, which could result in poorer adaptation of adults to the free-range environment. Although it is typically not feasible to provide outdoor access to pullets, rearing enrichments may be a method of improving the pullet's developmental environment (Campbell et al., 2019). Regularly changing novel objects might simulate the frequently changing and unpredictable free-range environment and improve hen's adaptation to stressful change as adults (Campbell et al., 2018a). Enriching with structures to enhance perching and encourage spatial navigation may increase physical development and spatial awareness (Gunnarsson et al., 2000) which could benefit ranging hens. Management approaches that include rearing enrichments in their pullet stages may improve adaptability, reduce stress, and improve hen immunity (Arbona et al., 2011; Moe et al., 2010), thus reducing disease prevalence or infections in free-range hens.

The current study was conducted with the aim to evaluate the effect of individual ranging patterns on health parameters through post-mortem examination of free-range layers from different rearing enrichments. We predicted improved health and welfare of enriched over control hens and both benefits and consequences of ranging.

\section{Materials \& Methods}

\section{Ethical statement}

All research was approved by the University of New England Animal Ethics Committee (AEC17-092).

\section{Animals and Housing}

A total of 1386 Hy-Line ${ }^{\circledR}$ Brown layers were used for this study. The chicks and pullets were reared indoors at the Kirby poultry facility and the adults were housed in the Laureldale freerange facility at the University of New England, Armidale, NSW, Australia. Day-old chicks (including additional chicks delivered by the hatchery but not transferred to the laying facility) were reared across 16 weeks within 9 pens $(6.2 \mathrm{~m} \mathrm{~L} \mathrm{x} 3.2 \mathrm{~m} \mathrm{~W})$ distributed across three separate rooms. The pullets were exposed to 3 separate rearing enrichment treatments. These included a control group having no extra materials over the pen standard of rice hulls as floor litter, a novelty group where novel objects were added and changed at weekly intervals (e.g. balls, bottles, bricks, brooms, brushes, buckets, containers, pet toys, plastic pipes, strings) and a structural group where four custom-designed $\mathrm{H}$-shaped perching structures $(\mathrm{L}, \mathrm{W}, \mathrm{H}=0.60 \mathrm{~m})$ with two solid panels and one open-framed side were provided. Each of the rooms had one pen replicate per treatment, balanced for location within rooms. Shade cloth hung on the wire pen 
159

160

161

162

163

164

165

166

167

168

169

170

171

172

173

174

175

176

177

178

179

180

181

182

183

184

185

186

187

188

189

190

191

192

193

194

195

196

197

198

dividers visually isolating birds from each other. At 16 weeks of age, bird density was approximately $15 \mathrm{~kg} / \mathrm{m}^{2}$ or 9 pullets $/ \mathrm{m}^{2}$ (average $174-190$ pullets $/$ pen). Round feeders provided ad libitum access to commercially-formulated mash appropriate for the developmental stage and nipples supplied ad libitum water access. These resources were provided as per the current Australian Model Code of Practice for the Welfare of Animals - Domestic Poultry (Primary Industries Standing Committee, 2002). Artificial lighting and temperature schedules followed the recommended Hy-Line ${ }^{\circledR}$ Brown alternative management guidelines (Hy-Line Brown management guide, 2016) but the LED lighting was maintained at 100 lux as the pullets were destined for outdoor access (no natural light was present during rearing). Mechanical ventilation with heating operated as needed but no cooling system was present. Chicks were infra-red beaktrimmed at the hatchery with a vaccination schedule as per regulatory requirements and standard recommendations including vaccination against Newcastle disease, Marek's disease, fowl pox, fowl cholera, egg drop syndrome, Mycoplasma gallisepticum, Mycoplasma synoviae, infectious bronchitis, infectious laryngotracheitis, and avian encephalomyelitis.

At 16 weeks, 1386 pullets were transferred to the Laureldale free-range facility and remixed within pen replicates (extra delivered chicks that were grown out were rehomed). The hens were housed within their rearing treatments across 9 pens located in a single shed $(n=154$ hens/pen, indoor density approximately $9 \mathrm{hens} / \mathrm{m}^{2}$ ). The indoor pens were visually separated via shade cloth and included nest boxes ( 2 small and 1 large nest box), perches, round hanging feeders and water nipples to fulfil the requirements of the Australian Model Code of Practice for the Welfare of Animals - Domestic Poultry (Primary Industries Standing Committee, 2002). Rice hulls were used as floor litter material with one complete litter replacement mid-way through the flock cycle. The LED lighting schedule gradually increased to 16 hours light and 8 hours dark by 30 weeks of age with an average pen intensity of 10.0 ( $\pm 0.84 \mathrm{SE})$ lux (Lutron Light Meter, LX-112850; Lutron Electronic Enterprise CO., Ltd, Taipei, Taiwan) as measured at birds' eye height from 3 pen locations (front, middle, back) when the pop-holes were closed. This lux was the highest that could be achieved with the shed lighting system. The shed was fanventilated with no temperature or humidity control.

Each of the 9 pens was connected to an outdoor range area $(31 \mathrm{~m} \mathrm{~L} \mathrm{x} 3.6 \mathrm{~m} \mathrm{~W}$ for each pen, density approximately 1.4 hens $\left./ \mathrm{m}^{2}\right)$ which was accessed via two pop-hole openings $(18 \mathrm{~cm} \mathrm{~W} \mathrm{x}$ $36 \mathrm{~cm} \mathrm{H}$ ). The range area immediately after the pop-holes was $1.1 \mathrm{~m}$ of concrete path, then $1.6 \mathrm{~m}$ of river rock followed by a grassed area with no additional trees or shelter. The grassed area became denuded following both hen access and the winter season. Each range was visually divided by shade cloth hung along the wire fences. Hens were provided access to the outdoor area from 25 weeks of age (May 2018) for most of the day time via automatic opening and closing of the pop-holes. The pop-holes opened at 9:15 am and closed after sunset daily. This equated to approximately 9 hours of available ranging time across winter followed by approximately 11 hours of available ranging time after daylight saving time started (October 2018). 


\section{Radio-frequency identification (RFID) system}

All birds were banded with microchips (Trovan ${ }^{\circledR}$ Unique ID 100 (FDX-A operating frequency $128 \mathrm{kHz}$ ) glued into adjustable leg bands (Roxan Developments Ltd, Selkirk, Scotland) to track their movement in and out of the range pop-holes via radio-frequency identification (RFID) systems. The RFID systems were designed and supported by Microchips Australia Pty Ltd (Keysborough, VIC, Australia) with equipment developed and manufactured by Dorset Identification B.V. (Aalten, the Netherlands) using Trovan ${ }^{\circledR}$ technology. For a schematic of the RFID system, see (Campbell et al., 2018b). The system recorded the date and time of each tagged bird passing through and in which direction (onto the range, or into the pen) with a precision of $0.024 \mathrm{~s}$ (maximum detection velocity $9.3 \mathrm{~m} / \mathrm{s}$ ). Individual ranging data were collected daily from 25 until 65 weeks of age.

\section{RFID data and selection of hens}

RFID data from 56 until 64 weeks of age (54 days of data) were initially run through a customdesigned software program written in the 'Delphi' language (Bryce Little, CSIRO, Agriculture and Food, St Lucia, QLD, Australia) that filtered out any unpaired or 'false' readings that may occur if, for example, a hen sits inside the pop hole but does not complete a full transition onto the range or back into the pen. Once screened in this way, the data were used to select a sample of birds from each pen to conduct post-mortem examinations on. A total of 307 hens were selected across all of the 9 pens at 64 weeks of age. The selected hens were categorized as 'indoor' - accessed the outdoors on one or zero of the 54 days, 'low outdoor - accessed the range on 53 or 54 of the 54 days but only for 1 h 24 mins or less, and 'high outdoor' - accessed the range for 54 of 54 days for 5 h 12 mins to 9 h. Based on these criteria, a total of 95 indoor, 109 low outdoor and 104 high hens outdoor were selected from the flock. Maximum ranging times differed between pens, thus the 'high outdoor' birds were selected as the highest for their pen, resulting in the variation in hours. Where possible, hen selection was balanced across pens within treatments, but some pen replicates did show higher numbers of the extreme ranging patterns than others.

\section{Pre-mortem welfare assessment}

All the selected hens were weighed 4 to 5 days before dissection using electronic hanging scales (BAT1; VEIT Electronics, Moravany, Czech Republic). The external health and welfare parameters including feather loss at different body parts (neck, chest, back, wing, vent, tail) and footpad lesions were assessed using the scoring system described by Tauson et al. (2005). In this scoring system, 4 scores were available for feather coverage with a score 4 indicating minimal feather damage, whereas a score 1 indicated bare skin. The back of the neck was scored separately from the front of the neck and was not included in the analyses as the majority of damage on the neck front was believed to have resulted from rubbing on the feeder rims rather than pecking. A maximum score of 24 could be obtained for feather condition across 6 body parts. Footpad lesions were scored as a 4 for a normal footpad with no lesions (an additional 
239

240

241

242

243

244

245

246

247

248

249

250

251

252

253

254

255

256

257

258

259

260

261

262

263

264

265

266

267

268

269

270

271

272

273

274

275

276

277

category to the Tauson et al. (2005) system) and a score 1 for swollen, infected bumble foot. The exact number of fresh or healing comb wounds were counted, and toenail length was measured in mm using a seamstress tape measure. Beaks were scored as 0,1 , or 2 indicating no, mild, or moderate damage respectively. The birds were also examined for any other external signs of injury or illness, such as body wounds, bleeding, abnormal respiratory sound etc., but none were observed in these hens. All selected hens were tagged with an additional leg band for identification in their home pen to enable later capture.

\section{Post-mortem health examination}

Post-mortem examinations of the selected 307 hens were carried out across two days at 65 weeks of age at a separate post-mortem facility located $5.5 \mathrm{~km}$ from the free-range facility. The selected hens of a single pen were transported to the post-mortem lab up to 2 hours prior to the dissection using plastic carrier crates. Hens were killed using $\mathrm{CO}_{2}$ to maintain hen physical structure for later scanning. Immediately after the $\mathrm{CO}_{2}$ administration and cessation of all hen movement, the birds were opened by a veterinarian to examine the health condition of the hens (presence/absence of diseases) by inspecting the visceral organs for any abnormalities including haemorrhage, tumours, caseous necrosis and/or other exudates, the respiratory system (nares and trachea) for any haemorrhage, inflammation or exudates and the reproductive system for signs of salpingitis, being egg bound, or other abnormalities. Whether the hen was in production or not was determined by examination of the ovary and presence of active or regressing follicles. The spleen, gizzard, and right adrenal gland were removed and weighed (to the nearest $\mathrm{mg}$ ) from each of the selected birds. The gizzard was emptied prior to weighing with surrounding connective tissue and fat removed. The jejunum, duodenum and ileum were opened longitudinally and the number of Ascaridia galli worms in each bird recorded. This is one of the most prevalent nematode parasites present within Australian commercial free-range systems (Dao et al., 2018). The carcass weight of each bird was taken after post-mortem examination (minus the removed organs and small intestines) prior to the Computed Tomography (CT) scanning.

\section{CT scanning and image analysis}

Following post-mortem examination, all birds were scanned using a HiSpeed QX/I (2003) CT scanner (GE Medical Systems). Scans were performed using a voltage of $100 \mathrm{kV}$, a current of $80 \mathrm{~mA}$, a pitch of $0.75: 1$, a field of view of $500 \times 500 \mathrm{~mm}$, a thickness of $2.5 \mathrm{~mm}$, and a spacing of $3.75 \mathrm{~mm}$ per rotation. Resultant images had a pixel matrix of $512 \times 512$, and hence a pixel resolution of $2.384 \mathrm{~mm}^{3}$.

CT image stacks of each individual hen were analyzed using ImageJ (Rasband W.S., ImageJ, U.S. National Institutes of Health, Bethesda, Maryland, USA, https://imagej.nih.gov/ij/, 1887-2018) to generate pixel frequency plots against greyscale pixel values (0-255). Greyscale value density was defined using a linear regression parameterized to known carcass weights $(\mathrm{g})$ 
278

279

280

281

282

283

284

285

286

287

288

289

290

291

292

293

294

295

296

297

298

299

300

301

302

303

304

305

306

307

308

309

310

311

312

313

314

315

316

317

recorded immediately prior to scanning. As such, the linear regression between density ( $\rho$, $\mu \mathrm{g} / \mathrm{mm}^{3}$ ) and greyscale value $(\mathrm{x})$ was given as:

$\rho=10.19( \pm 0.4546 \sigma) \cdot x$

where $\sigma$ is a standard deviation.

The weight of individual chicken (w, g) was therefore given as:

$\mathrm{w}=\sum_{\mathrm{x}=0}^{255} \mathrm{y} \cdot \alpha \cdot \rho \cdot 1000000$

[Eq. 2]

where $y$ is the frequency of each greyscale value; $\alpha$ is the pixel resolution $\left(2.384 \mathrm{~mm}^{3}\right)$; and $\rho$ is density $\left(\mu \mathrm{g} / \mathrm{mm}^{3}\right.$, Eq. 1).

Body composition of each chicken was estimated assuming that the density of raw chicken fat was $\leq 865.64 \mu \mathrm{g} / \mathrm{mm}^{3}$ (https://www.aqua-calc.com/page/densitytable/substance/chicken-coma-and-blank-broilers-blank-or-blank-fryers-coma-and-blankseparable-blank-fat-coma-and-blank-raw), and that bone was identified as having a greyscale value of $255(2598.45 \mu \mathrm{g} \pm 0.4546 \sigma)$, with the remaining mass being attributed to muscle. Some hens contained an egg which was not removed prior to scanning and was classified the same as bone in the images. All hens with an egg present $(1 / 0)$ were later identified $(n=87)$ and removed from the analysis.

\section{Assessment of the keel bone}

Following CT scanning, the keel bone was excised from each hen to assess deformities and damage. All keel bones were stored at $-20^{\circ} \mathrm{C}$ until thawed for processing. For processing, the fleshes on the keels were removed using a knife and scissors. The defects on the keels were examined by two experimenters using a visual scoring system for bending of the spine that was classified as low, moderate, or high based on the extent (Figure 1). The two observers scored each bone independently and then immediately confirmed scores to ensure agreement for each bone. The dorsal surface of the tip of the keels were also observed for the presence of calluses to indicate healed fractures and the number of calluses were counted and recorded by two observers in agreement (Figure 2). No fresh pre-mortem fractures were observed.

\section{Data and statistical analyses}

Statistical analyses were conducted in JMP ${ }^{\circledR} 14.0$ (SAS Institute, Cary, NC, USA) with $\alpha$ set at 0.05. Data were transformed where needed but the raw values are presented in the tables and graphs. Non-significant interactions were removed from the final models and post-hoc Student's t-tests were applied to the least-squares means where significant differences were present. For the pre-mortem welfare assessment data, the per hen values $(n=307$ hens $)$ for the total feather score (up to 24) and the number of comb wounds were square-root transformed. The body weight and toenail length measurements per bird were compiled. General Linear Mixed Models 
318 (GLMM) were fitted to each welfare variable with rearing enrichment treatments and ranging

319

320

321

322

323

324

325

326

327

328

329

330

331

332

333

334

335

336

337

338

339

340

341

342

343

344

345

346

347

348

349

350

351

352

353

354

355

356

357

patterns as fixed effects including their interaction and bird ID nested within pen, rearing treatment, and ranging as a random effect. Restricted maximum likelihood estimation methods were applied.

The feather scores for each body part and footpad damage scores were compiled per individual hen and the effects of rearing treatment, ranging, and their interaction were tested using ordinal logistic regressions.

The body composition data (muscle, fat, bone in grams) from the CT scans $(n=307)$, postmortem parameters including organ weights (liver, spleen, right adrenal gland, and empty gizzard proportional to live body weight), and worm counts were compiled per individual bird (n $=306$ hens, data from 1 bird were missing). The relative organ weight proportional data were logit-transformed for analysis but expressed as percentages in the table. The worm count data were square-root transformed. GLMMs were fitted to test the fixed effects of rearing treatment and ranging groups including their interaction, with bird ID nested within pen, rearing treatment, and ranging as a random effect. The bone composition data of hens with an egg present $(\mathrm{n}=87)$ were excluded from the analysis and data from 220 hens only were used.

Although a total of 307 birds were dissected, only 300 keels were assessed due to labelling issues with 7 keels. The qualitative data for the keel bones was compiled per individual bird $(n=300)$ including the overall presence of damage to the keel bone (yes/no), the type of keel spine bending, the presence (yes/no) and the number of calluses on the tips of the keels. Pearson's Chi-square tests for differences between rearing treatments and ranging patterns were conducted separately for each variable of each set of data. When conducting the Chi-square test with one treatment, the other treatment effect was blocked for each of the variables. The counts of calluses were square-root transformed and analysed using a GLMM to test the effects of rearing treatment and ranging groups including their interaction, with bird ID nested within pen, rearing treatment, and ranging as a random effect.

\section{Results}

\section{Pre-mortem welfare assessment}

Enriched rearing treatments did not affect the live weight of hens $\left(\mathrm{F}_{2,302}=0.11, P=0.90\right)$ but the high outdoor hens had the lowest body weight $\left(\mathrm{F}_{(2,302)}=10.90, P<0.0001\right.$, Table 1$)$. There was no interaction between rearing treatment and ranging $(P=0.32)$. The total feather score of hens was the lowest in the control rearing treatment $\left(\mathrm{F}_{(2,302)}=31.41, P<0.0001\right)$ indicating the most feather loss in these birds compared with the enriched hens (Table 1). The total feather score was highest in the high outdoor hens $\left(\mathrm{F}_{(2,302)}=18.06, P<0.0001\right)$ compared with low outdoor and indoor hens indicating the least feather loss in these birds (Table 1). There was no interaction between rearing treatment and ranging $(P=0.11)$. The control hens had more comb wounds than the novelty hens but neither group differed from the structural group $\left(\mathrm{F}_{(2,302)}=3.63, P=0.03\right.$, Table 1). The high outdoor hens had fewer comb wounds compared with the indoor hens but neither ranging group differed from the low outdoor hens $\left(\mathrm{F}_{(2,302)}=3.08, P=0.04\right.$, Table 1$)$.

Peer] reviewing PDF | (2019:11:43210:2:0:NEW 3 Feb 2020) 
358

359

360

361

362

363

364

365

366

367

368

369

370

371

372

373

374

375

376

377

378

379

380

381

382

383

384

385

386

387

388

389

390

391

392

393

394

395

396

397

There was no interaction between rearing treatment and ranging $(P=0.44)$. Rearing treatment did not affect toenail length $\left(\mathrm{F}_{(2,302)}=2.19, P=0.11\right)$, but the indoor hens had the longest nails and the high outdoor hens had the shortest $\left(\mathrm{F}_{(2,302)}=86.84, P<0.0001\right.$, Table 1). There was no interaction between rearing treatment and ranging patterns on any of the pre-mortem variables $(P$ $\geq 0.11)$.

A higher percentage (95\%) of hens from the structural group showed feet with no damage (score 4) compared with the control (93\%) and novelty groups (93\%). A higher percentage of hens $(97 \%)$ from the low outdoor ranging groups showed no footpad damage (score 4) compared with the high outdoor (88\%) and indoor hens (95\%). Only $0.92 \%$ of hens from the novelty group and $0.96 \%$ hens from the high outdoor ranging group showed the worst footpad condition (score 1). Ordinal logistic regression analysis showed ranging patterns significantly affected the footpad damage of hens $(\chi 2=7.07, \mathrm{df}=2, P=0.03)$ with high ranging increasing damage but the rearing treatments did not $(\chi 2=0.86, \mathrm{df}=2, P=0.65)$. There was no interaction between rearing treatment and ranging patterns $(P=0.14)$.

For other health issues examined pre-mortem, $0.01 \%$ of hens showed a prolapse. Most of the hens $(91.86 \%)$ had no defects on the beaks with a scoring of ' 0 ', but $0.06 \%$ and $0.03 \%$ of hens had beaks with a score of ' 1 ' for mild and a score of ' 2 ' for moderate defects, respectively.

\section{Feather scores of individual hen body parts}

Analyses of the feather scores of separate hen body parts showed rearing treatments had significant effects on plumage damage to the back of the neck, chest, and back with control hens showing the poorest feather coverage (Table 2). Ranging patterns had significant effects on plumage damage to the chest with high outdoor hens showing the greatest plumage coverage (Table 2). There were no significant interactions between rearing treatments and ranging groups (all $P \geq 0.07$ ).

\section{Post-mortem parameters}

Rearing treatments affected the relative weight of the spleen $\left(\mathrm{F}_{(2,301)}=4.82, P=0.01\right)$ with the spleens from the novelty hens having lower weight than the spleens from the control hens but neither group differed from the structural group (Table 3). The high outdoor birds' relative spleen weight was the highest $\left(\mathrm{F}_{(2,301)}=4.44, P=0.01\right)$. The high outdoor hens had higher empty gizzard weights than the indoor hens $\left(\mathrm{F}_{(2,301)}=3.22, P=0.04\right)$ but there was no effect of rearing treatment $\left(\mathrm{F}_{(2,301)}=0.85, P=0.43\right)$. Both the rearing treatments and ranging had no significant effects on the relative liver and adrenal weights (Table 3 ). There was no overall significant effect of rearing treatments on the number of worms in the GI tract $\left(\mathrm{F}_{(2,301)}=2.30, P\right.$ $=0.10$ ), but post-hoc tests (which are more focussed to differentiate the clear visual differences in means, (Hsu 1996) showed the novelty hens had more worms than the control hens and neither group differed from the structural hens (Table 3). There was no effect of ranging group on the number of worms $\left(\mathrm{F}_{(2,301)}=1.15, P=0.32\right)$. There were no significant interactions between rearing treatment and ranging for any of the measured variables (all $P \geq 0.21$ ). 
402

403

404

405

406

407

408

409

410

411

412

413

414

415

416

417

418

419

420

421

422

423

424

425

426

427

428

429

430

431

432

433

434

435

436

Post-mortem examination also revealed all hens under study except one, were in production. There were no disease lesions observed on the respiratory system of the hens. One bird had a fatty liver, one peritonitis and one had keel adhesion. A cystic right oviduct was also present in $0.04 \%$ of hens.

\section{Body composition}

There was a trend for an effect of rearing treatment on body fat $\left(\mathrm{F}_{(2,302)}=2.80, P=0.06\right)$ with the novelty group showing lower body fat $(\mathrm{LSM} \pm \mathrm{SEM}=122.39 \pm 1.78)$ than the control group $(\mathrm{LSM} \pm \mathrm{SEM}=128.15 \pm 1.91)$ but neither differed from the structural group $(\mathrm{LSM} \pm \mathrm{SEM}=$ $126.99 \pm 1.83)$. Ranging had a significant effect on body fat $\left(\mathrm{F}_{(2,302)}=19.70, P<0.0001\right)$ and muscle $\left(\mathrm{F}_{(2,302)}=11.49, P<0.0001\right)$ with the high outdoor birds showing the lowest amount of fat and muscle (Figure 3$)$. There was no effect of rearing treatment on muscle mass $\left(\mathrm{F}_{(2,302)}=\right.$ $0.25, P=0.78)$. There was a trend for an effect of rearing treatments $\left(\mathrm{F}_{(2,215)}=2.84, P=0.06\right)$ on bone mass with the post-hoc tests showing the novelty hens had higher bone mass than the control group but the structural group did not differ significantly from either (Figure 4). The ranging patterns had no significant effect $\left(\mathrm{F}_{2,215}=1.95, P=0.14\right)$ on bone mass of the hens. There were also no significant interactions of rearing treatments and ranging on any measured variable (all $P \geq 0.16$ ).

\section{Keel bone damage}

The free-range hens from different rearing treatments and ranging patterns showed no significant differences in the overall presence of keel bone defects, presence of spine bending, spine bending types, and the presence of callus formation on the dorsal surface of keel tips (all $P \geq 0.19$, Table 4). The rearing treatments $\left(\mathrm{F}_{(2,295)}=0.40, P=0.67\right)$, ranging patterns $\left(\mathrm{F}_{(2,295)}=1.31, P=0.27\right)$ and their interaction $(P=0.55)$ had no effect on the number of calluses on the tip of the dorsal surface of the keels.

\section{Discussion}

This study assessed the effects of different rearing enrichments and outdoor ranging patterns on the external and internal health and welfare of free-range hens at 64 to 65 weeks of age. Hens enriched during rearing had better feather coverage than control hens and the hens enriched with novel objects had fewer comb wounds than the control hens. The novelty hens also had lower spleen weights than the control birds. Range access had multiple clear effects with the hens that ranged the most showing lower total body weight, lower fat and muscle content, better plumage, shorter toenails, the highest spleen weight and fewer comb wounds than the indoor birds. Rearing or ranging did not affect the prevalence and degree of keel bone damage, but most sampled birds showed some type of damage. Overall, enriched rearing environments still had some effects on hens at the later stages of the production cycle but subsequent range use patterns had the greatest impact. 
437

438

439

440

441

442

443

444

445

446

447

448

449

450

451

452

453

454

455

456

457

458

459

460

461

462

463

464

465

466

467

468

469

470

471

472

473

474

475

476

Hens reared with enrichments had better plumage indicating a persistent effect of rearing conditions through until later in the production cycle. Multiple studies have documented the positive long-term effects of providing substrates during rearing where opportunities to forage and dust bathe are suggested to prevent the development of feather pecking (reviewed in Rodenburg et al., 2013; Van de Weerd \& Elson, 2006) although substrate availability during the laying period is also critical (Rodenburg et al., 2013). All birds in this study were both reared and then housed with access to a floor litter substrate but the additional pen enrichments still had positive impacts. Huber-Eicher \& Audigé (1999) did find that access to perches during rearing significantly reduced the risk of feather pecking. The structural rearing group had access to elevated perches for 16 weeks, and some of the objects initially placed in the novelty pens did allow chicks to perch (e.g. bricks, containers) with later objects provided to allow pecking/exploration (e.g. strings, pet toys). The increased complexity of the enriched pens may have improved behavioural development or provided more opportunities for the pullets to regulate their social interactions by having elevated escape areas. These positive effects of enrichments contrast with the findings by Hartcher et al. (2015) who reported that rearing enrichments of polypropylene pecking strings, whole oats and increased litter depth from 12 days of age had no effect on the plumage of adult free-range hens at 43 weeks of age. These discrepancies between results might have occurred due to the variation in novel objects of the different studies or age at first provision. Pullets did not show feather damage at the end of rearing (unpublished data) but it is unclear whether pecking behaviour in the control hens resulted from behavioural patterns established during rearing, and/or if the adult control hens were more susceptible to environmental stress in the free-range setting which triggered the development of the negative pecking behaviour.

The novelty hens had lower relative spleen weights than the control hens but showed a higher worm count. Differences in spleen size can be related to parasite burden (John, 1995) where a greater burden increases spleen size. Spleen size can also reduce with stress where Odihambo Mumma et al. (2006) found that an adrenocorticotropin (ACTH) treatment to experimentally increase stress in layers reduced relative spleen weight compared with control hens. Thus, it is unclear the causes for the differences in spleen size in the current study. Additionally, only adult $A$. galli worms (no other infection life stages or other parasites) were counted in the current study and other measured organs were not affected by rearing treatments. Therefore, further study would be needed to confirm any relationship between rearing enrichments, stress, infections and spleen size in adult hens.

The outdoor hens had relatively heavier spleens. This heavier weight could be a result of reduced stress through outdoor access and potential behavioural freedom. However, experimental exposure to a lipopolysaccharide stressor from E. coli increased relative spleen weight and thus the outdoor hens may have had higher spleen weights through exposure to more pathogens (Shini et al., 2009). Increased spleen weight is a very general response to many types of infections although other factors might be involved (Smith \& Hunt, 2004) such as seasonal influence (John, 1994). Outdoor hens were previously reported to be more stressed as indicated 
477 by the heterophil/lymphocyte ratio (Mahboub et al., 2004). However, variation in spleen weight

478 might be dependent on type of stressors and further research is needed to confirm any

479 relationship between ranging and spleens. There was no significant difference in the $A$. galli

480 parasite burden between indoor and outdoor hens which is supported by recent findings by

481 (Bestman et al., 2019) and previous research showing high parasite loads for hens housed in litter

482 systems (Permin et al., 1999) suggesting all hens in the free-range system can become infected.

483 However, further studies, particularly on commercial farms, are still required to confirm the

484

485

486

487

488

489

490

491

492

493

494

495

496

497

498

499

500

501

502

503

504

505

506

507

508

509

510

511

512

513

514

515

516 individual-level relationship between parasitic burden and ranging patterns.

The hens that ranged the most showed the best plumage coverage which provides further support to previous research. Several studies have demonstrated better plumage in individuals, or flocks that show more frequent use of the outdoor range (De Koning et al., 2018; Lambton et al., 2010; Mahboub et al., 2004; Rodriguez-Aurrekoetxea \& Estevez, 2016), or who range farthest when outdoors (Chielo et al., 2016). It might be that hens outdoors are able to or are motivated to engage in more foraging compared with hens indoors (Campbell et al., 2017) where a lack of foraging is often redirected to feather pecking, causing plumage damage (Bestman et al., 2009; Gilani et al., 2013; Rodenburg et al., 2013). This result contrasts with that of Larsen et al. (2018 who found no association between outdoor ranging and plumage condition of Hy-Line ${ }^{\circledR}$ Brown hens in commercial Australian conditions. It is also possible that better plumage coverage led to more ranging if hens were able to thermoregulate more effectively and/or avoid sun exposure on bare skin.

The outdoor rangers also had shorter toenails which confirms a previous finding at the same experimental research facility (Campbell et al., 2017) as well as research comparing between hens from free-range or caged systems (Yilmaz Dikmen et al., 2016). This is probably due to increased walking and scratching outside which allows hens to appropriately manage growing nail length.

Hens that ranged the most showed the lowest body weight, specifically, lower body fat and muscle, but not lower skeletal mass. The high outdoor hens showed an average body weight $(1.95 \mathrm{~kg})$ lower than the indoor hens but were within the limit of the expected body weight by breed standards (1.90 - $2.02 \mathrm{~kg}$; Hy-Line Brown management guide, 2016). Previous research has found some evidence of a similar negative relationship between body weight and range use, but not at all measured age points (Campbell et al., 2017) and some authors have found the opposite relationship (Singh et al., 2016). This negative relationship might be due to the ingestion of vegetation, insects or grit during ranging and thus consumption of less formulated food (Singh \& Cowieson, 2013). This would also correspond with the higher empty gizzard weight observed in the ranging hens, similar to findings of larger gizzards in free-range versus caged hens (Yang et al., 2014). The reduction in body weight might also be a result of greater energy utilisation during locomotion, although greater exercise opportunities have previously been shown to increase bone and muscle development (Casey-Trott et al., 2017a; Regmi et al., 2016) which was not found in the outdoor hens. Other measured skeletal properties rather than overall mass may have revealed differences between ranging groups although recent work 
517 showed no effect of ranging on multiple tibial measurements across hens from a commercial 518 aviary-free-range system (Kolakshyapati et al., 2019). There is currently limited knowledge in 519 the comparative activity levels of hens that remain indoors, and this warrants further 520 investigation.

521 The present study suggested no effect of rearing enrichments and ranging patterns on keel 522 damage of free-range hens. This coincides with observations on commercial farms that assessed 523 damage via both dissection (Kolakshyapati et al., 2019) and palpation (Larsen et al., 2018) and

524 found no association between individual ranging and keel damage. It was expected that rearing 525 with structural enrichments may have reduced the later occurrence of fractures (Casey-Trott et 526 al., 2017b), but this was not supported by the current study. The actual relationship between 527 range use and keel damage might be inconclusive because painful keel fractures might prevent 528 birds passing through the pop holes (Richards et al., 2012) and ultimately reduces range access. 529 The novelty rearing treatment increased bone mass relative to the control birds which may have 530 been a result of novel objects that allowed perching in the first 2 weeks of life (e.g. overturned 531 containers). The birds in the structural treatment were first observed starting to perch at 2 weeks 532 of age onwards. Further specific bone measures would confirm any effects of the rearing 533 treatments on skeletal development.

534

535

\section{Conclusion}

536 The study showed that rearing enrichments had long-term effects on adult free-range hens, particularly in reducing the degree of plumage damage. However, subsequent individual ranging patterns by the hens had a stronger influence on their health and welfare with high outdoor use resulting in better plumage, fewer comb wounds, shorter nail length, higher spleen and gizzard weight, but lower body weight, fat and muscle. Rearing enrichments are thus recommended for long-term positive effects on hen welfare, but management of range access may have the strongest impact on bird welfare. This study was conducted in an experimental setting with small flock sizes and low incidence of infection. Large commercial groups of layers are likely to be exposed to more pathogens where outdoor access may have different effects on hen susceptibility. Similar long-term studies on commercial free-range farms would confirm the benefits and consequences of different ranging patterns.

\section{Acknowledgements}

We would like to thank all staff and students of UNE and CSIRO who contributed in technical and husbandry assistance, and data collection for this study. Thank you to M. Raue (UNE) for assistance with the CT scanning. Thank you to P. Scott and N. Fernando (Scolexia Pty. Ltd) for vaccination advice during pullet rearing.

\section{References}


555

556

557

558

559

560

561

562

563

564

565

566

567

568

569

570

571

572

573

574

575

576

577

578

579

580

581

582

583

584

585

586

587

588

589

590

591

592

593

594

Arbona DV, Anderson KE, and Hoffman JB. 2011. A comparison of humoral immune function in response to a killed newcastle's vaccine challenge in caged vs. free-range Hy-Line brown layers. International Journal of Poultry Science 10:315-319.

Bestman M, Koene P, and Wagenaar J-P. 2009. Influence of farm factors on the occurrence of feather pecking in organic reared hens and their predictability for feather pecking in the laying period. Applied Animal Behaviour Science 121:120-125. doi:10.1016/j.applanim.2009.09.007

Bestman M, Niekerk T van, Haas EN de, Ferrante V, and Gunnarsson S. 2019. Role of range use in infections with parasites in laying hens. 188, Proceedings of the $53^{\text {rd }}$ International Society for Applied Ethology, August 5-9, Norway. Abstract. doi: http://hdl.handle.net/2434/676206

Bestman M, and Wagenaar J-P. 2014. Health and welfare in Dutch organic laying hens. Animals 4:374-390. doi:10.3390/ani4020374

Bray HJ, and Ankeny RA. 2017. Happy Chickens lay tastier eggs: Motivations for buying freerange eggs in Australia. Anthrozoös 30:213-226. doi:10.1080/08927936.2017.1310986

Campbell DLM, de Haas EN, and Lee C. 2019. A review of environmental enrichment for laying hens during rearing in relation to their behavioral and physiological development. Poultry Science 98:9-28. doi:10.3382/ps/pey319

Campbell DLM, Hinch GN, Downing JA, and Lee C. 2016. Fear and coping styles of outdoorpreferring, moderate-outdoor and indoor-preferring free-range laying hens. Applied Animal Behaviour Science 185:73-77. doi:10.1016/j.applanim.2016.09.004

Campbell DLM, Hinch GN, Downing JA, and Lee C. 2017. Outdoor stocking density in freerange laying hens: effects on behaviour and welfare. Animal 11:1036-1045. doi:10.1017/S1751731116002342

Campbell DLM, Hinch GN, Downing JA, and Lee C. 2018a. Early enrichment in free-range laying hens: Effects on ranging behaviour, welfare and response to stressors. Animal 12:575-584. doi:10.1017/S1751731117001859

Campbell DLM, Horton BJ, and Hinch GN. 2018b. Using radio-frequency identification technology to measure synchronised ranging of free-range laying hens. Animals 8:210. doi:10.3390/ani8110210

Casey-Trott TM, Korver DR, Guerin MT, Sandilands V, Torrey S, and Widowski TM. 2017a. Opportunities for exercise during pullet rearing, Part I: Effect on the musculoskeletal characteristics of pullets. Poultry Science 96:2509-2517. doi: 10.3382/ps/pex059

Casey-Trott TM, Guerin MT, Sandilands V, Torrey S, and Widowski TM. 2017b. Rearing system affects prevalence of keel-bone damage in laying hens: a longitudinal study of four consecutive flocks. Poultry Science 96:2029-2039. doi: 10.3382/ps/pex026

Chielo LI, Pike T, and Cooper J. 2016. Ranging behaviour of commercial free-range laying hens. Animals 6:28. doi:10.3390/ani6050028

Crespo N, and Esteve-Garcia E. 2001. Dietary fatty acid profile modifies abdominal fat deposition in broiler chickens. Poultry Science 80:71-78. doi:10.1093/ps/80.1.71

Peer) reviewing PDF | (2019:11:43210:2:0:NEW 3 Feb 2020) 
595

596

597

598

599

600

601

602

603

604

605

606

607

608

609

610

611

612

613

614

615

616

617

618

619

620

621

622

623

624

625

626

627

628

629

630

631

632

633

Dao HT, Hunt PW, Sharma N, Swick RA, Barzegar S, Hine B, McNally J, and Ruhnke I. 2018. Analysis of antibody levels in egg yolk for detection of exposure to Ascaridia galli parasites in commercial laying hens. Poultry Science 98:179-187. doi:10.3382/ps/pey383

Fossum O, Jansson DS, Etterlin PE, and Vågsholm I. 2009. Causes of mortality in laying hens in different housing systems in 2001 to 2004. Acta Veterinaria Scandinavica 51:3. doi:10.1186/1751-0147-51-3

Gilani A-M, Knowles TG, and Nicol CJ. 2013. The effect of rearing environment on feather pecking in young and adult laying hens. Applied Animal Behaviour Science 148:54-63. doi: 10.1016/j.applanim.2013.07.014

Gunnarsson S, Yngvesson J, Keeling LJ, and Forkman B. 2000. Rearing without early access to perches impairs the spatial skills of laying hens. Applied Animal Behaviour Science 67:217-228. doi: 10.1016/S0168-1591(99)00125-2

Hartcher KM, Hickey KA, Hemsworth PH, Cronin GM, Wilkinson SJ, and Singh M. 2016. Relationships between range access as monitored by radio frequency identification technology, fearfulness, and plumage damage in free-range laying hens. Animal 10:847853. doi:10.1017/S1751731115002463

Hartcher KM, Tran MK, Wilkinson SJ, Hemsworth PH, Thomson PC, and Cronin GM. 2015. Plumage damage in free-range laying hens: Behavioural characteristics in the rearing period and the effects of environmental enrichment and beak-trimming. Applied Animal Behaviour Science 164:64-72. doi: 10.1016/j.applanim.2014.12.011

Heerkens JLT, Delezie E, Ampe B, Rodenburg TB, and Tuyttens FAM. 2016. Ramps and hybrid effects on keel bone and foot pad disorders in modified aviaries for laying hens. PoultrySscience 95:2479-2488. doi: 10.3382/ps/pew157

Höglund J, and Jansson DS. 2011. Infection dynamics of Ascaridia galli in non-caged laying hens. Veterinary Parasitology 180:267-273. doi:10.1016/j.vetpar.2011.03.031

Hsu J. 1996. Multiple comparisons: theory and methods: Chapman and Hall/CRC, Boca Raton, Florida, USA.

Huber-Eicher B, and Audigé L. 1999. Analysis of risk factors for the occurrence of feather pecking in laying hen growers. British Poultry Science 40:599-604. doi: 10.1080/00071669986963

Hy-Line Brown management guide. 2016. Management guide for Hy-Line Brown laying hen in alternative systems. Available at https://www.hyline.com/userdocs/pages/B_ALT_COM_ENG.pdf(accessed 15 May 2019).

Janczak AM, and Riber AB. 2015. Review of rearing-related factors affecting the welfare of laying hens. Poultry Science 94:1454-1469. doi: 10.3382/ps/pev123

John JL. 1994. The avian spleen: A neglected organ. The Quarterly Review of Biology 69:327351. doi: $10.1086 / 418649$

John JL. 1995. Parasites and the avian spleen: helminths. Biological Journal of the Linnean Society 54:87-106. doi:10.1111/j.1095-8312.1995.tb01024.x 
634 Kaufmann F, Daş G, Sohnrey B, and Gauly M. 2011. Helminth infections in laying hens kept in

635

636

637

638

639

640

641

642

643

644

645

646

647

648

649

650

651

652

653

654

655

656

657

658

659

660

661

662

663

664

665

666

667

668

669

670

671

672

673 organic free range systems in Germany. Livestock Science 141:182-187. doi:10.1016/j.livsci.2011.05.015

Kolakshyapati M, Flavel RJ, Sibanda TZ, Schneider D, Welch MC, and Ruhnke I. 2019. Various bone parameters are positively correlated with hen body weight while range access has no beneficial effect on tibia health of free-range layers. Poultry Science, in press. doi: $10.3382 / \mathrm{ps} / \mathrm{pez} 487$

Koning C de, Kitessa SM, Barekatain R, and Drake K. 2018. Determination of range enrichment for improved hen welfare on commercial fixed-range free-range layer farms. Animal Production Science. doi: 10.1071/AN17757

Lambton SL, Knowles TG, Yorke C, and Nicol CJ. 2010. The risk factors affecting the development of gentle and severe feather pecking in loose housed laying hens. Applied Animal Behaviour Science 123:32-42. doi:10.1016/j.applanim.2009.12.010

Larsen H, Cronin GM, Gebhardt-Henrich SG, Smith CL, Hemsworth PH, and Rault J-L. 2017. Individual ranging behaviour patterns in commercial free-range layers as observed through RFID tracking. Animals 7:21. doi:10.3390/ani7030021

Larsen H, Hemsworth PH, Cronin GM, Gebhardt-Henrich SG, Smith CL, and Rault J-L. 2018. Relationship between welfare and individual ranging behaviour in commercial free-range laying hens. Animal:1-9. doi: 10.1017/S1751731118000022

Lay DC, Fulton RM, Hester PY, Karcher DM, Kjaer JB, Mench JA, Mullens BA, Newberry RC, Nicol CJ, and O'sullivan NP. 2011. Hen welfare in different housing systems. Poultry Science 90:278-294. doi: 10.3382/ps.2010-00962

Mahboub HDH, Müller J, and Von Borell E. 2004. Outdoor use, tonic immobility, heterophil/lymphocyte ratio and feather condition in free-range laying hens of different genotype. British Poultry Science 45:738-744. doi: 10.1080/00071660400014267

Mashaly MM, Hendricks GL, 3rd, Kalama MA, Gehad AE, Abbas AO, and Patterson PH. 2004. Effect of heat stress on production parameters and immune responses of commercial laying hens. Poultry Science 83:889-894. doi: 10.1093/ps/83.6.889

Moe RO, Guemene D, Bakken M, Larsen HJS, Shini S, Lervik S, Skjerve E, Michel V, and Tauson R. 2010. Effects of housing conditions during the rearing and laying period on adrenal reactivity, immune response and heterophil to lymphocyte $(\mathrm{H} / \mathrm{L})$ ratios in laying hens. Animal 4:1709-1715. doi:10.1017/S175173111000100X

Odihambo Mumma J, Thaxton JP, Vizzier-Thaxton Y, and Dodson WL. 2006. Physiological stress in laying hens. Poultry Science 85:761-769. doi.org/10.1093/ps/85.4.761

Permin A, Bisgaard M, Frandsen F, Pearman M, Kold J, and Nansen P. 1999. Prevalence of gastrointestinal helminths in different poultry production systems. British Poultry Science 40:439-443. doi.org/10.1080/00071669987179

Pettersson IC, Weeks CA, Wilson LRM, and Nicol CJ. 2016a. Consumer perceptions of freerange laying hen welfare. British Food Journal 118:1999-2013. doi: 10.1108/BFJ-022016-0065 
674 Pettersson IC, Freire R, and Nicol CJ. 2016b. Factors affecting ranging behaviour in commercial

675

676

677

678

679

680

681

682

683

684

685

686

687

688

689

690

691

692

693

694

695

696

697

698

699

700

701

702

703

704

705

706

707

708

709

710

711

712 free-range hens. World's Poultry Science Journal 72:137-150. doi:10.1017/S0043933915002664

Primary Industries Standing Committee. 2002. Model code of practice for the welfare of animals: Domestic poultry. Collingwood, Victoria, Australia: CSIRO PUBLISHING.

Regmi P, Smith N, Nelson N, Haut RC, Orth MW, and Karcher DM. 2016. Housing conditions alter properties of the tibia and humerus during the laying phase in Lohmann white Leghorn hens. Poultry Science 95:198-206. doi: 10.3382/ps/pev209

Renema RA, Robinson FE, Newcombe M, and McKay RI. 1999. Effects of body weight and feed allocation during sexual maturation in broiler breeder hens. 1. Growth and carcass characteristics. Poultry Science 78:619-628. doi.10.1093/ps/78.5.619

Richards GJ, Wilkins LJ, Knowles TG, Booth F, Toscano MJ, Nicol CJ, and Brown SN. 2012. Pop hole use by hens with different keel fracture status monitored throughout the laying period. Veterinary Record 170:494-494. doi: 10.1136/vr.100489

Rodenburg TB, Krimpen MM van, Jong IC de, Haas EN de, Kops MS, Riedstra BJ, Nordquist RE, Wagenaar JP, Bestman M, and Nicol CJ. 2013. The prevention and control of feather pecking in laying hens: identifying the underlying principles. World's Poultry Science Journal 69:361-374. doi:10.1017/S0043933913000354

Rodriguez-Aurrekoetxea A, and Estevez I. 2016. Use of space and its impact on the welfare of laying hens in a commercial free-range system. Poultry Science 95:2503-2513. doi: $10.3382 / \mathrm{ps} /$ pew 238

Sherwin CM, Nasr MAF, Gale E, Petek M, Stafford K, Turp M, and Coles GC. 2013. Prevalence of nematode infection and faecal egg counts in free-range laying hens: relations to housing and husbandry. British Poultry Science 54:12-23. doi: 10.1080/00071668.2012.757577

Shini S, Shini A, and Huff GR. 2009. Effects of chronic and repeated corticosterone administration in rearing chickens on physiology, the onset of lay and egg production of hens. Physiology \& Behavior 98:73-77. doi:10.1016/j.physbeh.2009.04.012

Singh M, and Cowieson AJ. 2013. Range use and pasture consumption in free-range poultry production. Animal Production Science 53:1202-1208. doi.org/10.1071/AN13199

Singh M, Hernandez CE, Lee C, Hinch G, and Cowieson AJ. 2016. Wanderers versus stay at home: who has the better guts. p 14-17. Proceedings of the 27th Australian Poultry Science Symposium, 14-17 February, Sydney, Australia.

Singh M, Ruhnke I, de Koning C, Drake K, Skerman AG, Hinch GN, and Glatz PC. 2017. Demographics and practices of semi-intensive free-range farming systems in Australia with an outdoor stocking density of $\leq 1500$ hens/hectare. PLoS One 12:e0187057. doi: 10.1371/journal.pone.0187057

Smith KG, and Hunt JL. 2004. On the use of spleen mass as a measure of avian immune system strength. Oecologia 138:28-31. doi: 10.1007/s00442-003-1409-y 
713 Sun JM, Richards MP, Rosebrough RW, Ashwell CM, McMurtry JP, and Coon CN. 2006. The

714

715

716

717

718

719

720

721

722

723

724

725

726

727 relationship of body composition, feed intake, and metabolic hormones for broiler breeder females. Poultry Science 85:1173-1184. doi.org/10.1093/ps/85.7.1173

Tauson R, Kjaer J, Maria GA, Cepero Ra, and Holm K-E. 2005. Applied scoring of integument and health in laying hens. Animal Science Papers and Reports, 23:153-159.

Weerd HA van de, and Elson A. 2006. Rearing factors that influence the propensity for injurious feather pecking in laying hens. World's Poultry Science Journal 62:654-664. doi: 10.1079/WPS2006119

Yang HM, Yang Z, Wang W, Wang ZY, Sun HN, Ju XJ, and Qi XM. 2014. Effects of different housing systems on visceral organs, serum biochemical proportions, immune performance and egg quality of laying hens. European Poultry Science 78. doi: 10.1399/eps.2014.48

Yilmaz Dikmen B, İpek A, Şahan Ü, Petek M, and Sözcü A. 2016. Egg production and welfare of laying hens kept in different housing systems (conventional, enriched cage, and free range). Poultry Science 95:1564-1572. doi:10.3382/ps/pew082 
Figure 1

Different types of spine bending of keel bones

Keel (a) indicates a spine with no bending, (b) low bending, (c) moderate bending and (d) indicates high bending in the spine. The white arrows indicate the specific part of bending on the spine. 


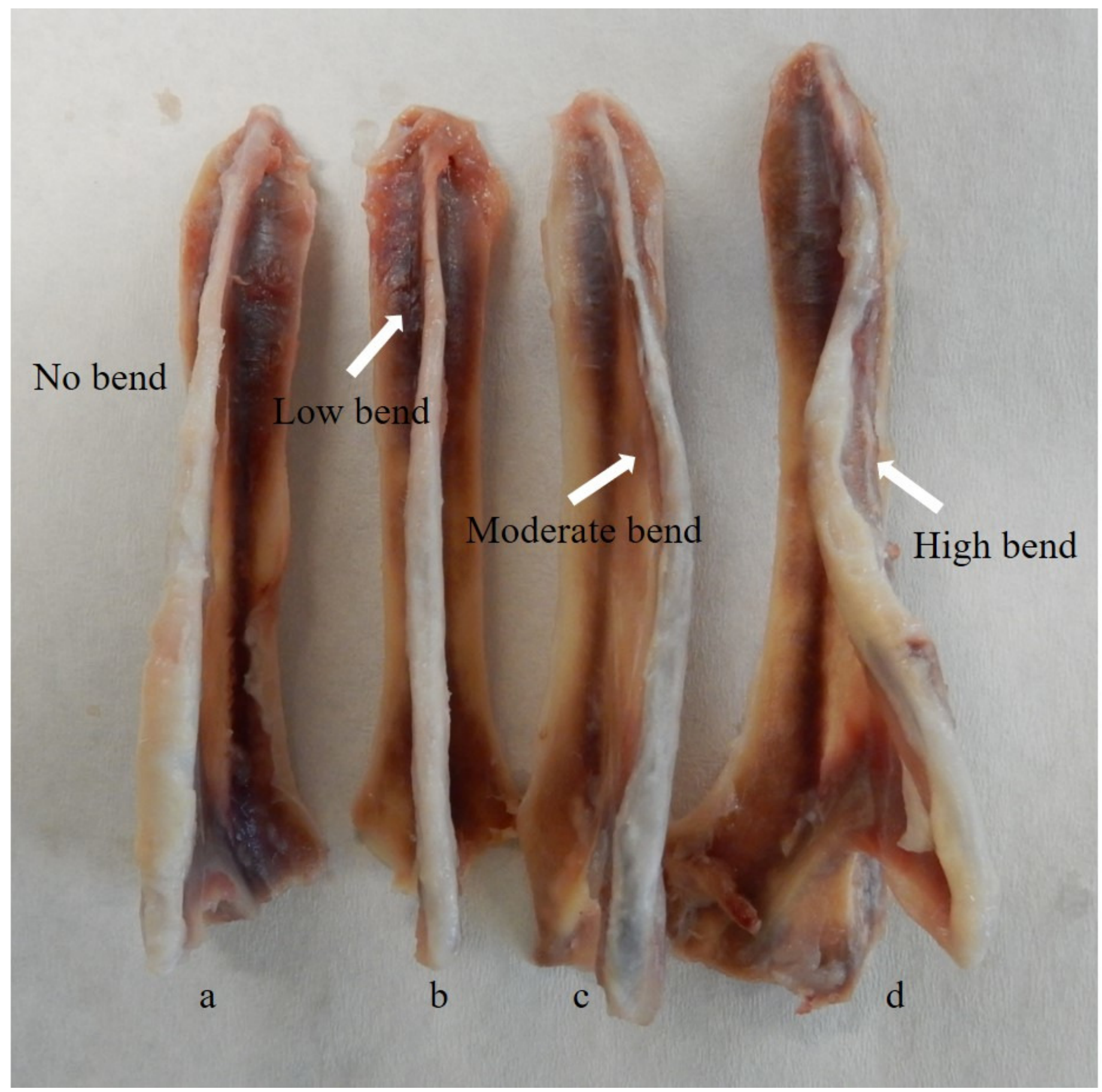




\section{Figure 2}

Calluses on the dorsal surface of keel bones.

(a) indicates a keel surface with no calluses, but (b) shows two calluses as indicated by the white arrows.

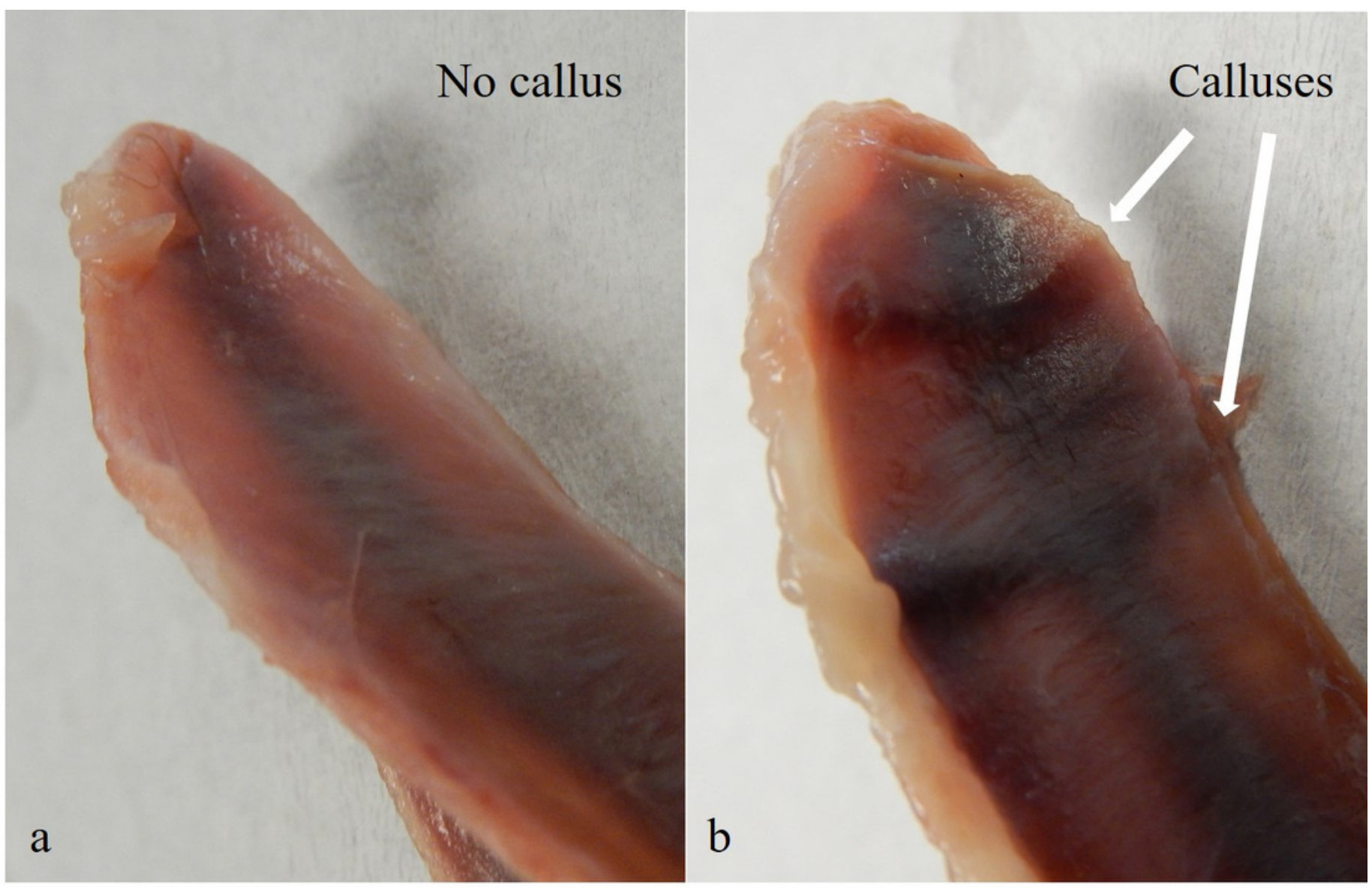




\section{Figure 3}

The relative CT-scanned body composition of hens from different range use patterns.

The least squares means \pm standard error of the mean of fat $(A)$ and muscle $(B)$ are presented from hens at 65 weeks of age that did not range (indoor), or ranged daily for low or high amounts of time. ${ }^{a, b}$ Dissimilar superscript letters indicate significant differences between ranging patterns $(P<0.0001)$. 


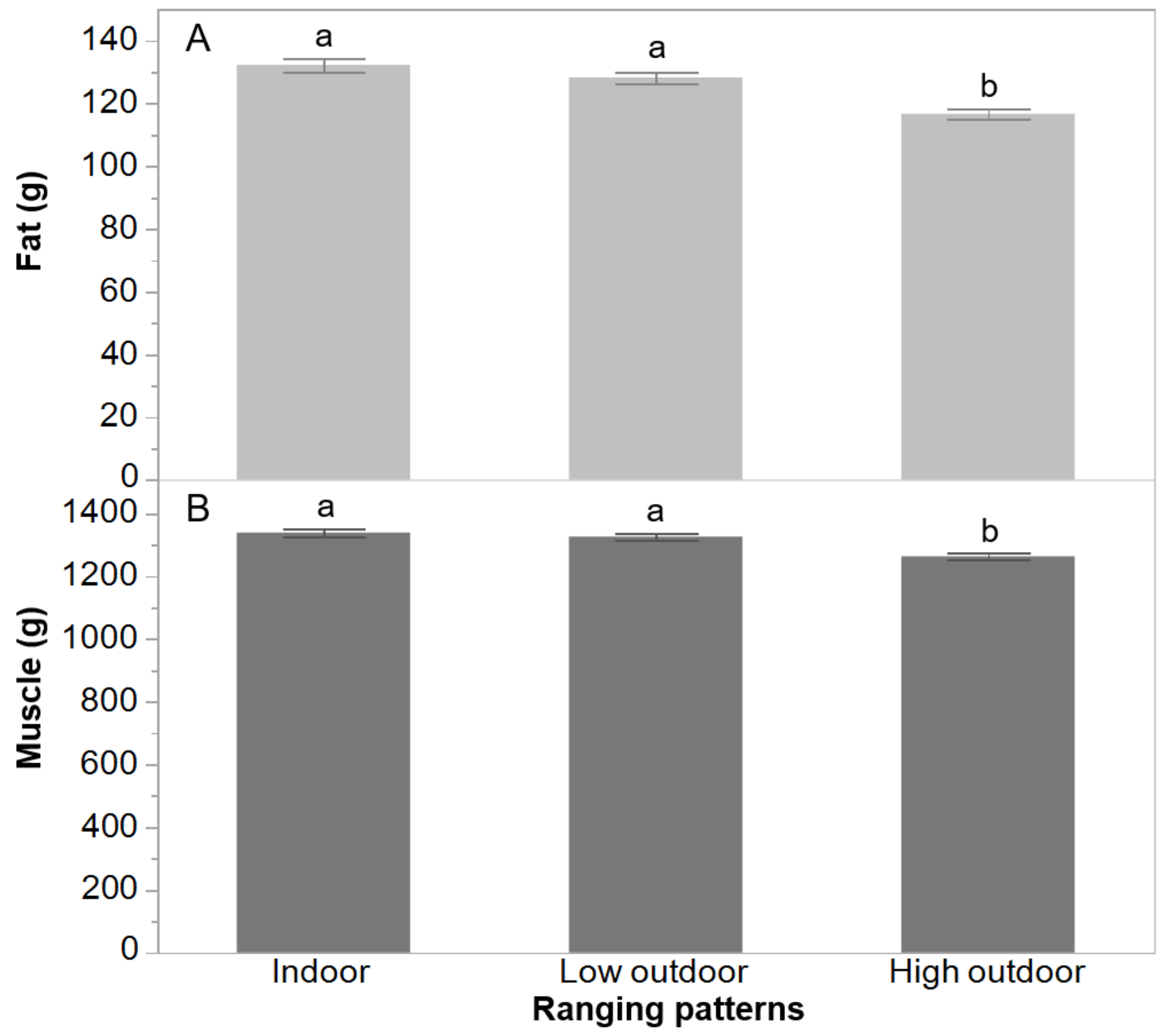




\section{Figure 4}

CT-scanned bone mass of hens from different rearing treatments.

The least squares means \pm standard error of the means are presented for free-range hens

from control, novelty or structural rearing treatments at 65 weeks of age. ${ }^{a, b}$ Dissimilar superscript letters indicate significant differences between rearing treatments as identified by a post-hoc Student's t-test. Only the data from the hens that had no eggs present during scanning were considered $(n=220)$. 


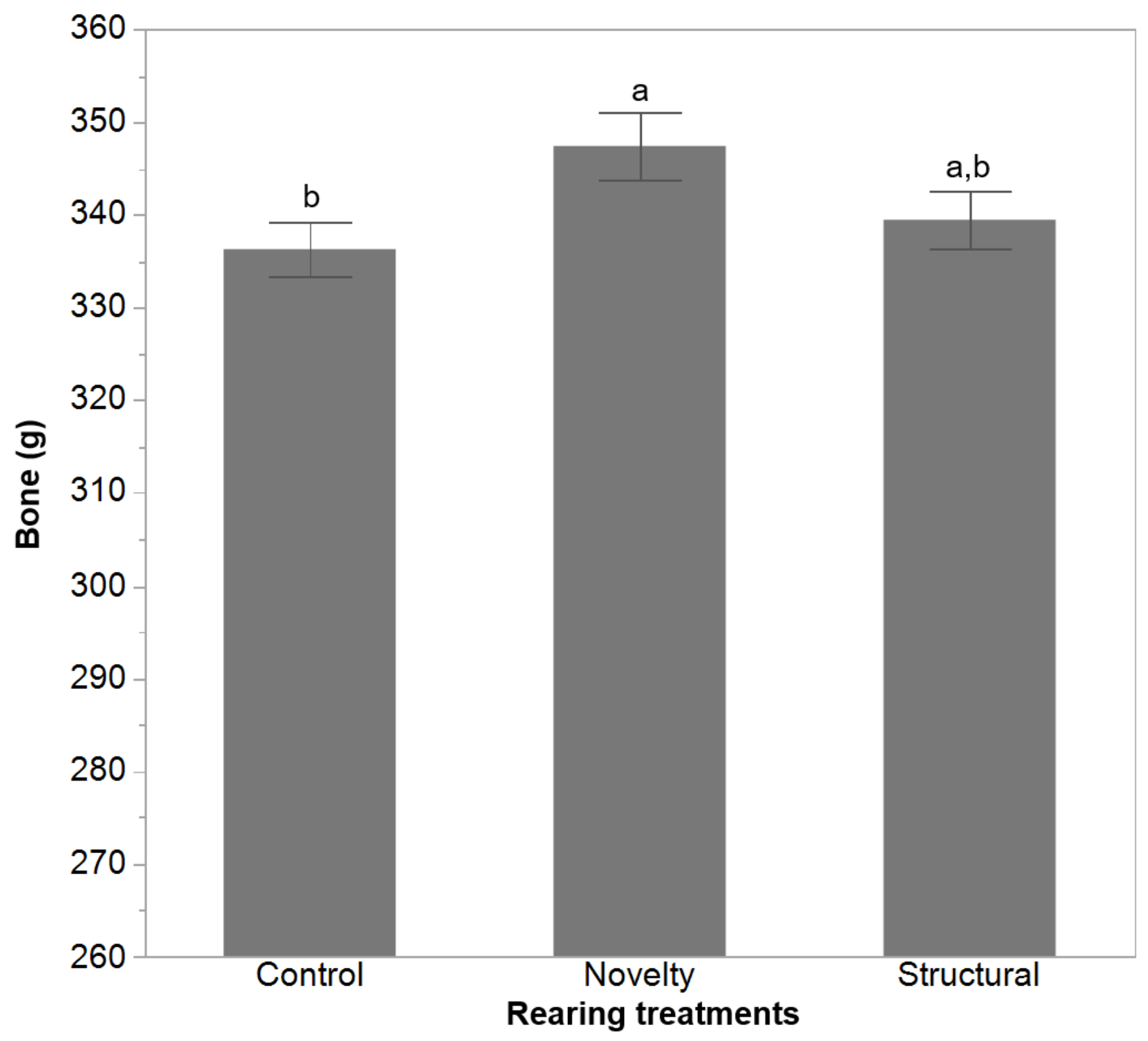




\section{Table $\mathbf{1}$ (on next page)}

The welfare parameters of free-range hens at 64 weeks of age.

The least squares means \pm standard error of the mean are presented for hens from different rearing treatments (control, novelty, structural) and ranging patterns (indoor, low outdoor, high outdoor). ${ }^{a, b}$ Dissimilar superscript letters indicate significant differences between rearing enrichments or ranging patterns $(P<0.05)$. Raw values are presented with the analyses conducted on transformed data. 


\begin{tabular}{llllll}
\hline Variable & Category & $\begin{array}{l}\text { Live weight } \\
(\mathrm{kg})\end{array}$ & $\begin{array}{l}\text { Feather score } \\
(\text { out of } 24)\end{array}$ & $\begin{array}{l}\text { Number of } \\
\text { comb wounds }\end{array}$ & $\begin{array}{l}\text { Nail length } \\
(\mathrm{cm})\end{array}$ \\
\hline Rearing & Control & $2.01 \pm 0.02$ & $21.31 \pm 0.15^{\mathrm{b}}$ & $0.91 \pm 0.13^{\mathrm{a}}$ & $1.54 \pm 0.02$ \\
enrichments & Novelty & $2.01 \pm 0.02$ & $22.83 \pm 0.14^{\mathrm{a}}$ & $0.48 \pm 0.12^{\mathrm{b}}$ & $1.58 \pm 0.02$ \\
& Structural & $2.02 \pm 0.02$ & $22.57 \pm 0.14^{\mathrm{a}}$ & $0.68 \pm 0.13^{\mathrm{a}, \mathrm{b}}$ & $1.53 \pm 0.02$ \\
& $\mathrm{P}-$ value & 0.90 & $<0.0001$ & 0.03 & 0.12 \\
Ranging & Indoor & $2.05 \pm 0.02^{\mathrm{a}}$ & $21.78 \pm 0.15^{\mathrm{b}}$ & $0.79 \pm 0.13^{\mathrm{a}}$ & $1.67 \pm 0.02^{\mathrm{a}}$ \\
& Low outdoor & $2.04 \pm 0.02^{\mathrm{a}}$ & $21.99 \pm 0.14^{\mathrm{b}}$ & $0.82 \pm 0.12^{\mathrm{a}, \mathrm{b}}$ & $1.61 \pm 0.02^{\mathrm{b}}$ \\
& High outdoor & $1.95 \pm 0.02^{\mathrm{b}}$ & $22.94 \pm 0.14^{\mathrm{a}}$ & $0.47 \pm 0.12^{\mathrm{b}}$ & $1.37 \pm 0.02^{\mathrm{c}}$ \\
& $\mathrm{P}-$ value & $<0.0001$ & $<0.0001$ & 0.04 & $<0.0001$ \\
\hline
\end{tabular}

1 


\section{Table 2 (on next page)}

The feather scores on different body parts for free-range hens.

The number and percentages of sampled hens within each group for each feather score category of six body parts (back of the neck, chest, back, wing, tail, vent) of free-range hens from different rearing treatments (control, novelty, structural) and ranging patterns (indoor, low outdoor, high outdoor) at 64 weeks of age. A score of 4 indicates the most feather coverage and a score of 1 the least, based on the scoring system of Tauson et al. (2005).

$\mathrm{N}=95$ for control, $\mathrm{N}=109$ novelty, $\mathrm{N}=103$ Structural, $\mathrm{N}=94$ indoor, $\mathrm{N}=109$ low outdoor and $\mathrm{N}=104$ for high outdoor groups. A ' - ' is given when no birds within any treatment group had that score.

* Chi-square tests were not performed due to insufficient data within each scoring group. 
1

\begin{tabular}{|c|c|c|c|c|c|c|c|}
\hline \multirow{2}{*}{$\begin{array}{l}\text { Feather } \\
\text { location }\end{array}$} & \multirow[t]{2}{*}{ Variable } & \multirow[t]{2}{*}{ Category } & \multicolumn{4}{|c|}{ Damage score n (\%) } & \multirow[t]{2}{*}{$\chi^{2}, \mathrm{df}, P$} \\
\hline & & & 1 & 2 & 3 & 4 & \\
\hline \multirow{6}{*}{$\begin{array}{l}\text { Neck } \\
\text { (back } \\
\text { only) }\end{array}$} & \multirow{3}{*}{$\begin{array}{l}\text { Rearing } \\
\text { enrichments }\end{array}$} & Control & - & $14(14.74)$ & $6(6.32)$ & $75(78.94)$ & \multirow{3}{*}{$\begin{array}{l}26.50,2 \\
<0.0001\end{array}$} \\
\hline & & Novelty & - & $0(0)$ & $6(5.50)$ & $103(94.5)$ & \\
\hline & & Structural & - & $2(1.94)$ & $0(0)$ & $101(98.06)$ & \\
\hline & \multirow[t]{3}{*}{ Ranging } & Indoor & - & $8(8.52)$ & $9(9.57)$ & $77(81.91)$ & \multirow[t]{3}{*}{ * } \\
\hline & & Low outdoor & - & $8(7.34)$ & $2(1.83)$ & $99(90.83)$ & \\
\hline & & High outdoor & - & $0(0)$ & $1(0.96)$ & $103(99.04)$ & \\
\hline \multirow[t]{6}{*}{ Chest } & \multirow{3}{*}{$\begin{array}{l}\text { Rearing } \\
\text { enrichments }\end{array}$} & Control & - & $49(51.58)$ & $13(13.68)$ & $33(34.74)$ & \multirow[t]{3}{*}{$6.88,2,0.03$} \\
\hline & & Novelty & - & $36(33.03)$ & $23(21.1)$ & $50(45.87)$ & \\
\hline & & Structural & - & $37(35.92)$ & $26(25.25)$ & $40(38.83)$ & \\
\hline & \multirow[t]{3}{*}{ Ranging } & Indoor & - & $45(47.87)$ & $20(21.28)$ & $29(30.85)$ & \multirow{3}{*}{$\begin{array}{l}33.26,2 \\
<0.0001\end{array}$} \\
\hline & & Low outdoor & - & $58(53.21)$ & $18(16.51)$ & $33(30.28)$ & \\
\hline & & High outdoor & - & $19(18.27)$ & $24(23.08)$ & $61(58.65)$ & \\
\hline \multirow[t]{6}{*}{ Back } & \multirow{3}{*}{$\begin{array}{l}\text { Rearing } \\
\text { enrichments }\end{array}$} & Control & - & $7(7.37)$ & $27(28.42)$ & $61(64.21)$ & \multirow{3}{*}{$\begin{array}{l}55.43,2 \\
<0.0001\end{array}$} \\
\hline & & Novelty & - & $0(0)$ & $1(0.92)$ & $108(99.08)$ & \\
\hline & & Structural & - & $1(0.97)$ & $9(8.74)$ & $93(90.29)$ & \\
\hline & \multirow[t]{3}{*}{ Ranging } & Indoor & - & $2(2.13)$ & $11(11.70)$ & $81(86.17)$ & \multirow[t]{3}{*}{$*$} \\
\hline & & Low outdoor & - & $2(1.83)$ & $17(15.6)$ & $90(82.57)$ & \\
\hline & & High outdoor & - & $4(3.85)$ & $9(8.65)$ & $91(87.5)$ & \\
\hline \multirow[t]{6}{*}{ Wing } & \multirow{3}{*}{$\begin{array}{l}\text { Rearing } \\
\text { enrichments }\end{array}$} & Control & - & - & $14(14.74)$ & $81(85.26)$ & \multirow[t]{3}{*}{$0.42,2,0.81$} \\
\hline & & Novelty & - & - & $14(12.84)$ & $95(87.16)$ & \\
\hline & & Structural & - & - & $12(11.65)$ & $91(88.35)$ & \\
\hline & \multirow[t]{3}{*}{ Ranging } & Indoor & - & - & $14(14.89)$ & $80(85.11)$ & \multirow[t]{3}{*}{$2.84,2,0.24$} \\
\hline & & Low outdoor & - & - & $17(15.6)$ & $92(84.4)$ & \\
\hline & & High outdoor & - & - & $9(8.65)$ & $95(91.35)$ & \\
\hline \multirow[t]{6}{*}{ Tail } & Rearing & Control & - & - & $19(20.0)$ & $76(80.0)$ & $4.70,2,0.10$ \\
\hline & enrichments & Novelty & - & - & $11(10.09)$ & $98(89.91)$ & \\
\hline & & Structural & - & - & $13(12.62)$ & $90(87.38)$ & \\
\hline & Ranging & Indoor & - & - & $19(20.21)$ & $75(79.79)$ & $5.13,2,0.08$ \\
\hline & & Low outdoor & - & - & $14(12.84)$ & $95(87.16)$ & \\
\hline & & High outdoor & - & - & $10(9.62)$ & $94(90.38)$ & \\
\hline Vent & Rearing & Control & $1(1.06)$ & $13(13.68)$ & $5(5.26)$ & $76(80.0)$ & $*$ \\
\hline & enrichments & Novelty & $0(0)$ & $1(0.92)$ & $0(0)$ & $108(99.08)$ & \\
\hline & & Structural & $0(0)$ & $0(0)$ & $5(4.85)$ & $98(95.15)$ & \\
\hline & Ranging & Indoor & $0(0)$ & $6(6.38)$ & $7(7.45)$ & $81(86.17)$ & $*$ \\
\hline & & Low outdoor & $1(0.92)$ & $4(3.67)$ & $2(1.83)$ & $102(93.58)$ & \\
\hline & & High outdoor & $0(0)$ & $4(3.85)$ & $1(0.96)$ & 99 (95.19) & \\
\hline
\end{tabular}




\section{Table 3 (on next page)}

The relative organ weights and worm counts of free-range hens.

The least squares means \pm standard error of the mean of the percentages of relative organ weights and worm counts of free-range hens at 65 weeks of age from different rearing treatments (control, novelty, structural) and ranging patterns (indoor, low outdoor, high outdoor). ${ }^{a, b}$ Dissimilar superscript letters indicate significant differences between rearing enrichments or ranging patterns $(P<0.05)$. Raw values are presented with the analyses conducted on transformed data. 


\begin{tabular}{|c|c|c|c|c|c|c|}
\hline Variable & Category & Liver weight (\%) & Spleen weight (\%) & Adrenal weight (\%) & Gizzard weight (\%) & Worms in GI tract $(\mathrm{N}$ \\
\hline \multirow{4}{*}{$\begin{array}{l}\text { Rearing } \\
\text { enrichments }\end{array}$} & Control & $2.59 \pm 0.04$ & $0.097 \pm 0.002^{\mathrm{a}}$ & $0.003 \pm 0.01$ & $1.72 \pm 0.03$ & $4.52 \pm 0.84$ \\
\hline & Novelty & $2.60 \pm 0.04$ & $0.089 \pm 0.002^{b}$ & $0.004 \pm 0.01$ & $1.67 \pm 0.02$ & $7.03 \pm 0.79$ \\
\hline & Structural & $2.51 \pm 0.04$ & $0.092 \pm 0.002^{\mathrm{ab}}$ & $0.025 \pm 0.01$ & $1.69 \pm 0.03$ & $5.66 \pm 0.80$ \\
\hline & Test statistics & $\mathrm{F}_{(2,301)}=2.23, \mathrm{P}=0.11$ & $\mathrm{~F}_{(2,301)}=4.82, \mathrm{P}=0.01$ & $\mathrm{~F}_{(2,301)}=1.82, \mathrm{P}=0.16$ & $\mathrm{~F}_{(2,301)}=0.85, \mathrm{P}=0.43$ & $\mathrm{~F}_{(2,301)}=2.30, \mathrm{P}=0.10$ \\
\hline \multirow[t]{4}{*}{ Ranging } & Indoor & $2.58 \pm 0.04$ & $0.091 \pm 0.002^{\mathrm{b}}$ & $0.004 \pm 0.01$ & $1.65 \pm 0.03^{\mathrm{b}}$ & $4.88 \pm 0.85$ \\
\hline & Low outdoor & $2.53 \pm 0.04$ & $0.089 \pm 0.002^{\mathrm{b}}$ & $0.024 \pm 0.01$ & $1.69 \pm 0.02^{\mathrm{ab}}$ & $5.59 \pm 0.78$ \\
\hline & High outdoor & $2.60 \pm 0.04$ & $0.097 \pm 0.002^{\mathrm{a}}$ & $0.003 \pm 0.01$ & $1.74 \pm 0.03^{\mathrm{a}}$ & $6.74 \pm 0.80$ \\
\hline & Test statistics & $\mathrm{F}_{(2,301)}=1.29, \mathrm{P}=0.28$ & $\mathrm{~F}_{(2,301)}=4.44, \mathrm{P}=0.01$ & $\mathrm{~F}_{(2,301)}=0.57, \mathrm{P}=0.57$ & $\mathrm{~F}_{(2,301)}=3.22, \mathrm{P}=0.04$ & $\mathrm{~F}_{(2,301)}=1.15, \mathrm{P}=0.32$ \\
\hline
\end{tabular}




\section{Table 4 (on next page)}

Keel bone defects of free-range hens.

The number and percentages of keel bone damage of free-range hens at 65 weeks of age from different rearing treatments (control, novelty, structural) and ranging patterns (indoor, low outdoor, high outdoor). Values of each category of damages are presented as $\mathrm{n}$ (\%) but the number of calluses on tips of keels are expressed as least squares means \pm standard error of mean (LSM $\pm \mathrm{SEM})$. For the number of calluses on tips, raw values are presented with the analyses conducted on transformed data. 


\begin{tabular}{|c|c|c|c|c|c|c|c|c|c|}
\hline \multirow[t]{2}{*}{ Treatment } & \multirow{2}{*}{ Category } & \multirow[t]{2}{*}{$\mathrm{N}$} & \multirow{2}{*}{$\begin{array}{c}\text { Damages } n \\
(\%) \\
\end{array}$} & \multirow{2}{*}{$\begin{array}{c}\text { Spine bending } \\
\mathrm{n}(\%)\end{array}$} & \multicolumn{3}{|c|}{ Spine bending types $\mathrm{n}(\%)$} & \multirow{2}{*}{$\begin{array}{c}\text { Callus formation } \\
\mathrm{n}(\%)\end{array}$} & \multirow{2}{*}{$\begin{array}{c}\text { Number of calluses } \\
\quad(\mathrm{LSM} \pm \mathrm{SEM})\end{array}$} \\
\hline & & & & & Low & Moderate & High & & \\
\hline \multirow{3}{*}{$\begin{array}{c}\text { Rearing } \\
\text { enrichments }\end{array}$} & Control & 91 & $71(78.02)$ & $57(62.64)$ & $46(50.55)$ & $7(7.69)$ & $4(4.40)$ & $40(43.96)$ & $0.71 \pm 0.11$ \\
\hline & Novelty & 106 & $82(77.36)$ & $68(64.15)$ & $51(48.11)$ & $7(6.60)$ & $10(9.43)$ & $42(39.62)$ & $0.70 \pm 0.10$ \\
\hline & Structural & 103 & $73(70.87)$ & $66(64.08)$ & $53(51.46)$ & $8(7.77)$ & $5(4.85)$ & $39(37.86)$ & $0.60 \pm 0.10$ \\
\hline Test statistics, df, $P$ & & & $\begin{array}{c}\chi^{2}=1.69,2 \\
0.43\end{array}$ & $\begin{array}{c}\chi^{2}=0.06,2 \\
0.97\end{array}$ & \multicolumn{3}{|c|}{$\chi^{2}=2.79,2,0.84$} & $\chi^{2}=0.78,2,0.68$ & $\mathrm{~F}_{(2,295)}=0.40,0.67$ \\
\hline \multirow[t]{3}{*}{ Ranging patterns } & Indoor & 92 & $68(73.91)$ & $57(61.96)$ & $42(45.65)$ & $9(9.78)$ & $6(6.52)$ & 39 (42.39) & $0.72 \pm 0.10$ \\
\hline & Low outdoor & 107 & $81(75.70)$ & $71(66.36)$ & $57(53.27)$ & $8(7.48)$ & $6(5.61)$ & $36(33.64)$ & $0.56 \pm 0.10$ \\
\hline & High outdoor & 101 & $77(76.24)$ & $63(62.38)$ & $51(50.50)$ & $5(4.95)$ & $7(6.93)$ & $46(45.54)$ & $0.73 \pm 0.10$ \\
\hline Test statistics, df, $P$ & & & $\begin{array}{c}\chi^{2}=0.15,2 \\
0.93\end{array}$ & $\begin{array}{c}\chi^{2}=0.52,2 \\
0.77\end{array}$ & \multicolumn{3}{|c|}{$\chi^{2}=2.60,2,0.86$} & $\chi^{2}=3.29,2,0.19$ & $\mathrm{~F}_{(2,295)}=1.31,0.27$ \\
\hline
\end{tabular}

